\title{
A Comparative Quality of Life Assessment of Herbal Drugs with Allopathic Drugs for the Treatment of Diabetic Complications
}

\author{
M. Sandhya Rani ${ }^{1, *}$, Rao.S.Pippalla ${ }^{2}$, G. Krishna Mohan ${ }^{1}$, Switi B. Gaikwad ${ }^{1}$ and Bhanu Prasad ${ }^{3}$ \\ ${ }^{I}$ Centre for Pharmaceutical Sciences, Institute of Science and Technology, Jawaharlal Nehru Technological University, \\ Hyderabad, Andhra Pradesh, India ${ }^{2}$ TP College of Pharmacy, Kakatiya University, Warangal, Andhra Pradesh, India; \\ ${ }^{3}$ Vignan Institute of Pharmaceutical Sciences, Deshmukhi, Nalgonda, Hyderabad, Andhra Pradesh, India
}

\begin{abstract}
Herbs help in healing and treating the root cause of the ailment by rejuvenating the system in protecting from chronic diseases like Diabetes thus helping in leading a better quality of life, hence this study is aimed at comparing the quality of life assessment of patients taking herbal medicine and allopathic medicine using generic and disease specific tools [SF-36-V2- Short form health survey and QOLID (Quality of life of Indian Diabetic Patients)]which helped in identifying the influence of various life domains in diabetic patients and a better understanding of the treatment goal of herbs in diabetes. Significant difference in the outcomes scores in between treatment groups, indicate that herbal treatment is far better in terms of quality of life of specific domains VT (Vitality), BP (Bodily Pain), MH (Mental Health), GH (General Health) and PF (Physical Functioning) compared to the allopathic treatment.
\end{abstract}

Keywords: Diabetes, diabetic complications, quality assessment.

\section{INTRODUCTION}

As our lifestyle is getting techno savvy, we are moving away from nature when choosing between modern western medicines and traditional and alternative medicines, but it is quite clear that synthetic remedies often cause more adverse side effects than the ailment they aim to relieve so more attention has been paid for the development of herbal medicines for well being of human. Balance of ingredients provided by the nature in their complete forms is well utilized by the body for healing and treatment of the root cause of the ailment thus rejuvenating the system which may help in leading a better quality of life. Interest in medicinal plants for the maintenance of Quality of life (QOL) and bioprospecting of new Traditional herbal drugs usage have been increased due to diverse cultures in India. This huge number of medicinal plant species allowed the evolution of many systems of herbal medicine and played an important role in health aid system [1].

Diabetes mellitus is a potential morbid condition, which has become highly prevalent worldwide, termed as a disorder rather than a disease [2]. Indigenous remedies have been used for treating diabetes mellitus since the time of Charaka and Sushrutha, Power of knowledge is the only way to improve the management of diabetes and it is a clarion call to public in healthcare to relook at the strategies for management. Traditional Alternative medicines control this disorder and alleviate the complications of Diabetes mellitus and also improve the well-being of diabetic patients.

*Address correspondence to this author at the Centre for Pharmaceutical Sciences, Institute of Science and Technology, Jawaharlal Nehru Technological University, Hyderabad, Andhra Pradesh, India; Tel: 9848061213; E-mail: Sandhya_uvts@yahoo.co.in
Longer duration of diabetes leads to greater complications. Complications related to diabetes pose a significant health care burden and a deterrent to overall quality of life. The cost of treatment for diabetic complications adds the health care costs. India thus faces a huge health care burden due to high prevalence.

In view of the increasing prevalence, there is a growing need to develop integrated approaches towards the prevention of Diabetes mellitus. Moreover uncontrolled diabetes appears to involve oxidative stress known to exhibit direct tissue damage properties, which may lead to many complications [3]. So detailed understanding of the disease is very essential as unlike any other disease, diabetes affects nearly all vital organs to a devastating extent.

The most widespread diabetic complications are cardiovascular complications and micro vascular complications [4, 5]. These debilitating complications take a huge toll on the quality of life to worsen the situation; the disease is rising at an alarming rate. So, an equal focus should be laid on both controlling the blood sugar level and preventing these complications to improve the of quality of life [2]. As per the world health organization an estimated $80 \%$ of the world relies on medicinal plants as their main source of healthcare, each part of the plant contains distinct properties according to the active constituents and used for different purposes. Experimental evidences suggest the involvement of free radicals in the pathogenesis of diabetes. Phenolics and Flavanoids can exert their antioxidant activity by various mechanisms like quenching the free radicals, by chelating of metal ions by inhibiting free radical generation [6]. So incorporation of phenols and flavanoids diet could contribute to potential management of hyperglycemia and disturbed lipid pattern and also help to alleviate complications of organ functions. 
In the past few decades the scientific community's growing interest in the field of quality of life in health economics and has led to significant development in methods applied to assess the Quality of life: Outcomes research is an evolving science $[7,8]$. The designed instruments help to tailor the treatment strategies. Individualized disease specific Quality of life measures give information about the patient's social, physical and psychological well being. So any interventions must take in to account individual perceptions, the use of descriptive measures and the preference-based measures [9]. Descriptive approaches are those that use instruments with various domains, allowing for broad description of state of health. Approaches based on preference are those that seek to capture the usefulness, attributed by individuals, of a given health status, listing various possible scenarios and variables, from perfect health to death, in quantitative scales. Preference is a broad concept which expresses an individual's desire for a certain state, involving both the concept of utility as the concept of values.

Measurement of health related quality of life has been facilitated by the development of self-report questionnaires that provide information from the perspective of the individual person and involves incorporation of patient's voice in to health care system.It is important to measure Health-related Quality of life (HRQOL) to assure that the treatment does not become more burdensome than the disease $[10,11]$. Measurement of health-related Quality of life is done either by using disease-specific or generic instruments. Diseasespecific measures may be more responsive to attributes of patients with the disease of interest, whereas generic measures are more generalizable across different diseases. In evaluation of diabetes specific health related Quality of life, careful assessment along the three major dimensionsPhysical ,social and Psychological functioning are essential [12].

The objectives of the present study were (1) to generate data from traditional systems and make basis for modern therapeutic regimen using herbs; (2) to provide high quality data that can be used to organize and manage medical care by implementing interventions that are aimed at solving the problems of the disease; and (3) to assess generic and disease specific QOL profiles of diabetic patients using SF-36 and QOLID questionnaires and to bring the science of outcomes measurement out of the laboratory.

\section{MATERIALS AND METHODS}

\section{Generic QOL Instruments}

SF-36 is an ever growing popular medical outcomes study, a short form health survey with 36-items (SF-36) applied for over 200 diseases and translated in 40 countries $[13,14]$. The instrument is well documented. It comprises of 8 -scale response profile useful in comparing the disease burden and differentiating the health benefits of different treatments. SF-36 version-2.0, an improved version of a SF-36 with only 36 questions that can provide the description of health through 8 health domain scales where five-level response choices included, intended to extend the range measured and increase the score precision without increasing the burden. There is no well-accepted measure that comprehen- sively evaluates the many aspects of diabetes-specific quality of life (DSQOL) [15].

Quality of Life Instrument for Indian Diabetic patients (QOLID) is a recently developed diabetic specific instrument which is specially designed for Indian diabetic patients. The questionnaire consists of 8 domains, a reliable and valid tool for assessing the quality of life of patients (Indian). The domains general health, physical health and physical endurance reflect the HRQOL, whereas the domains like treatment satisfaction, mental health, financial worries, diet satisfaction and symptom irritability reflect the Diabetes Specific Quality of Life [16].

\section{Specific QOL Questionnaire Tools}

The present study was conducted to assess the quality of life effectiveness of diabetes between the two treatments, one is the herbal medicine and the other is allopathic medicine for better follow up of health care. After careful review of the published questionnaire, best of what is currently available was selected using a convenient sample size of 40 .

\section{- Inclusion criteria:}

1. Type 2 diabetic patients

2. Age 35 to 65 years

3. Duration of diabetes more than one year

- Exclusion criteria:

1. Disease other than diabetes

2. Gestational Diabetes

3. Disability conditions

4.patients on any other therapy within the period of study.

1) SF-36 v $2^{\mathrm{TM}}$ Short form health survey (modified version)

2) Qolid (quality of life instrument for Indian diabetic patients)

\section{Assessment of Quality of life of Patients by Using Generic Questionnaire Tool-SF-36V2 $2^{\mathrm{TM}}$}

The Quality of life of each participant taking both herbal medicine and allopathic medicine was assessed using SF_36 v2 scale. It is a measure of generic type, involves 8-scale profile (Physical functioning-PF, Role-physical-RP, Bodily pain-BP, General health-GH, Vitality-VT, Social functioning-SF, Role-emotional-RE, Mental health-MH), available in both Standard (4-week) and acute (1-week) versions [17].

\section{Assessment of Quality of Life of Patients by Using Spe- cific QOLID Tools}

\section{Quality of Life Instrument for Indian Diabetic Patients:}

It is a tool used for the assessment of diabetes specific QOL in Indian subjects. The questionnaire was framed with the intention of reflecting HRQOL and also DSQOL, comprising of 8 domains with 34 items which cover all the aspects of Quality of life like General health (GH), Physical health (PH), Treatment Satisfaction (TS)), Mental health $(\mathrm{MH})$, Symptom irritability (SB), Financial worries (FW), 
Diet satisfaction (DS) and Physical endurance (PE)(75) Among the 8 domains, PHPE and $\mathrm{GH}$ are grouped in HRQOL whereas DS,SB,FW,TS and $\mathrm{MH}$ are related to DSQOL.

1. PH- 6 items measure the extent to which physical health interferes with daily activities, including accomplishing less than wanted, limitations in the kind of activities or difficulty in performing activities.

2. PE- 6 items designed for Physical activities measure how disease condition interferes with daily activities in a decreased time spent on activities and not working as carefully as usual.

3. GH- 4 items measure overall health status.

4. $\mathrm{TS}=$ Measures 4 items related to satisfaction with the current treatment.

5. $\mathrm{SB}=$ Measures 3 items related to symptoms observed in diabetic condition like thirst, hunger and frequent urination

6. $\mathrm{FW}=$ Measures 6 items related to costs and expenditure towards the diabetes management

7. $\mathrm{MH}=$ Measures 5 items of general mental health like how much satisfied are they for the support they get from others.

8. $\mathrm{DS}=$ Measures 3 items related to how often they restrict or avoid the food of choice because of diabetes.

The research was conducted in Apollo hospital, Banjara hills, Hyderabad and Ayurvedic Hospital, Government Research Institute (Ayurvedic), Erragadda, Hyderabad during the month of June-September 2012. The research project was approved by the institutional ethics committee of both the hospitals. The committee members - Dr M. Shyam sunder MD, Dr VS Patil MD, Dr S.S arangapani MD, Dr. B. Satyanarayana. The importance of the study was explained to each subject. The questionnaire was then administered to convenient sample of 40 subjects taking herbal medicine and allopathic medicine and assessed for their QOL profiles.

\section{The Statistical Analysis}

All the calculations were processed with Statistical package for the social sciences 23.0 and reliability analysis by means of Cronbach's alpha estimate. Scoring was given using a RAND score method.

\section{Descriptive Statistical Analysis}

As the study population comprised of 40 patients in each of the treatments, Mean, Standard Deviation and Inter Correlation Analysis between the variables of both herbal and synthetic scores were done by using Pearson's correlation coefficient.

\section{RESULTS}

\section{SF-36 QOL Measurement Tool}

It is important to measure health-related QOL in patients to assure that the treatment does not become more burdensome than the diseases. One of the HRQOL instruments ad- ministered in this current study was a multidimensional generic HRQOL -SF-36 measure, which is sensitive for treatments of herbal and synthetic. The comparison between the descriptive statistics of both the treatments is depicted in Table (1 and 2) and Figs. (1 and 2).

Pearson correlation coefficient was performed (intra and inter item correlations). The associations of domains of Herbal medicine and synthetic medicine by pearson's linear correlation were shown in the following Table 3 and Fig. (3).

The results of the present study showed that the domains VT, BP, MH, PF and GH showed a negative correlation and a closely negative correlation which in relation to scores indicates that herbal treatment is far better in terms of quality of life of the specific domains VTBPMHGH and PF compared to the synthetic treatment, whereas the other three domains (RE, SF and RP) which showed completely positive correlation indicates that there was no difference in QOL in these specific domains between the treatments. In aspects of Quality of life analysis, there was no difference found in the domains RP and RE.

\section{Intracorrelations of Each Domain with the pH}

When we estimated the correlations of each domain with the GH in the primary Domain interesting results emerged. Patients evaluated their health at five levels-- excellent, very good, good, fair, and poor. Intra correlations were calculated in both synthetic and herbal treatments have been presented in the Table $\mathbf{4}$ and Table 5 respectively

The above results were from QOL profiles of synthetic compounds indicating ratings of general health by the patients who were on synthetic compound. Very weak association was found between the domains $(\mathrm{MH}, \mathrm{SF}, \mathrm{BP}, \mathrm{pH})$ and General Health and seemingly RE and VT played a significant role when compared to contribution of other domains.

The above results were from QOL profiles of herbal compounds indicating ratings of General Health by the patients who were on herbal compound.

Very weak association was found between all the physical health parameters and General Health and seemingly mental health showed the strongest correlation with general health and played a special role in contribution to QOL when compared to contribution of other domains.

\section{QOLID Questionnaire}

The interpretation of treatment effects cannot be made only on these generic measures as they are less responsive. QOLID attempts to measure HRQOL in terms of satisfaction, worry, mental, physical and general health which are specifically linked to diabetes.

Analysis comparing patient reported outcomes found significant differences in between treatment groups in the specific domains like treatment satisfaction, Physical health, general health and mental health. Stronger impact was observed for treatmemt satisfaction, physical health and symptom irritability. Current results suggest that treatment with herbal medicine showed increased treatment satisfaction, vitality and was found to decrease symptom irritability. The future research on herbal medicine must pave its way 
Table 1. SF36 health profile of diabetic patients on synthetic medicines.

\begin{tabular}{|c|c|c|c|c|c|c|c|}
\hline No & Domain & Mean & Max.score & SD & Items & Flooring score & Ceiling score \\
\hline \hline $\mathbf{1}$ & PF & 40.95 & 75 & 17.46608 & 10 & 12.5 & 2.5 \\
\hline $\mathbf{2}$ & RP & 64.06 & 75 & 9.034966 & 4 & 20 & 7.5 \\
\hline $\mathbf{3}$ & BP & 47.13 & 87.5 & 19.56442 & 2 & 2.5 \\
\hline $\mathbf{4}$ & GH & 49.4 & 55 & 13.32177 & 5 & 2.5 \\
\hline $\mathbf{5}$ & VT & 42.25 & 70 & 11.31806 & 4 & 2.5 & 5 \\
\hline $\mathbf{6}$ & SF & 44.8 & 100 & 15.36404 & 3 & 2.5 \\
\hline $\mathbf{7}$ & RE & 59.29 & 83.3 & 9.524476 & 3 & 2.5 & 2.5 \\
\hline $\mathbf{8}$ & MH & 49.4 & 64 & 8.840457 & 5 & 2.5 \\
\hline
\end{tabular}

Table 2. SF36 health profile of diabetic Patients On herbal medicines treatment.

\begin{tabular}{|c|c|c|c|c|c|c|c|}
\hline No & Domain & Mean & Max.score & SD & Items & Flooring score & Ceiling score \\
\hline \hline $\mathbf{1}$ & PF & 50.9 & 95 & 15.0448 & 10 & 2.5 & 2.5 \\
\hline $\mathbf{2}$ & RP & 64.68 & 100 & 15.98464 & 4 & 10 & 10 \\
\hline $\mathbf{3}$ & BP & 56.7 & 100 & 24.81663 & 2 & 5 \\
\hline $\mathbf{4}$ & GH & 61.7 & 80 & 9.802668 & 5 & 2.5 & 12.5 \\
\hline $\mathbf{5}$ & VT & 63.25 & 85 & 11.28516 & 4 & 2.5 \\
\hline $\mathbf{6}$ & SF & 56.1 & 87.5 & 15.7476 & 3 & 17.5 \\
\hline $\mathbf{7}$ & RE & 52.89 & 100 & 25.29632 & 3 & 12.5 & 7.5 \\
\hline $\mathbf{8}$ & MH & 61.7 & 88 & 14.03695 & 5 & 10 \\
\hline
\end{tabular}

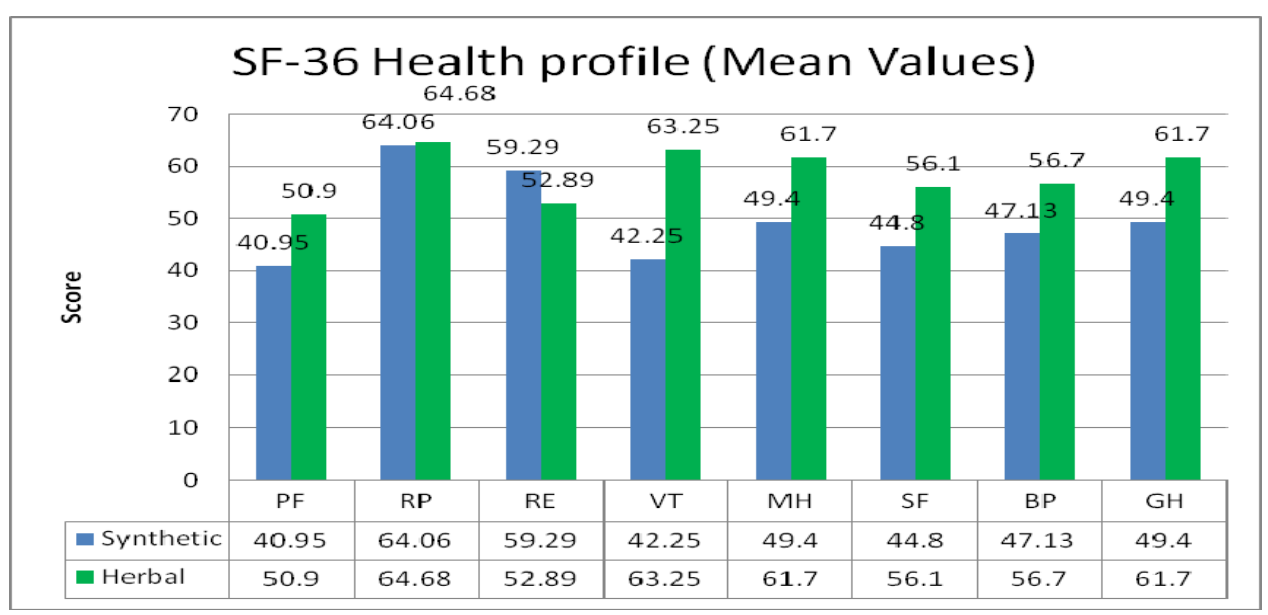

Fig. (1). Effect of treatment on generic health outcome measures(Mean scores) of diabetic patients.

concentrating on these specific domains of patient reported outcomes to improve the clinical effectiveness of the drug.

From the reliability studies for the internal consistency, the total alpha value was found to be 0.8203 and alpha for various variables ranged from 0.35 for financial worries to 0.89 for physical endurance in herbal treatment. The total alpha value was found to be 0.8248 and alpha for various variables ranged from 0.09 for diet satisfaction to 0.83 for symptom irritability in synthetic treatment. The general health alpha value was 0.73 for herbal treatment whereas alpha value 0.11 for synthetic treatment.

Standardized scores of the patients on herbal medicine were compared with those of synthetic medicine depicted in Table 4, 6, 7 and Fig. (4). The overall general health rating score for diabetics on herbal treatment was 79 with cronbach's alpha (compared to the synthetic treatment with 69.75). 


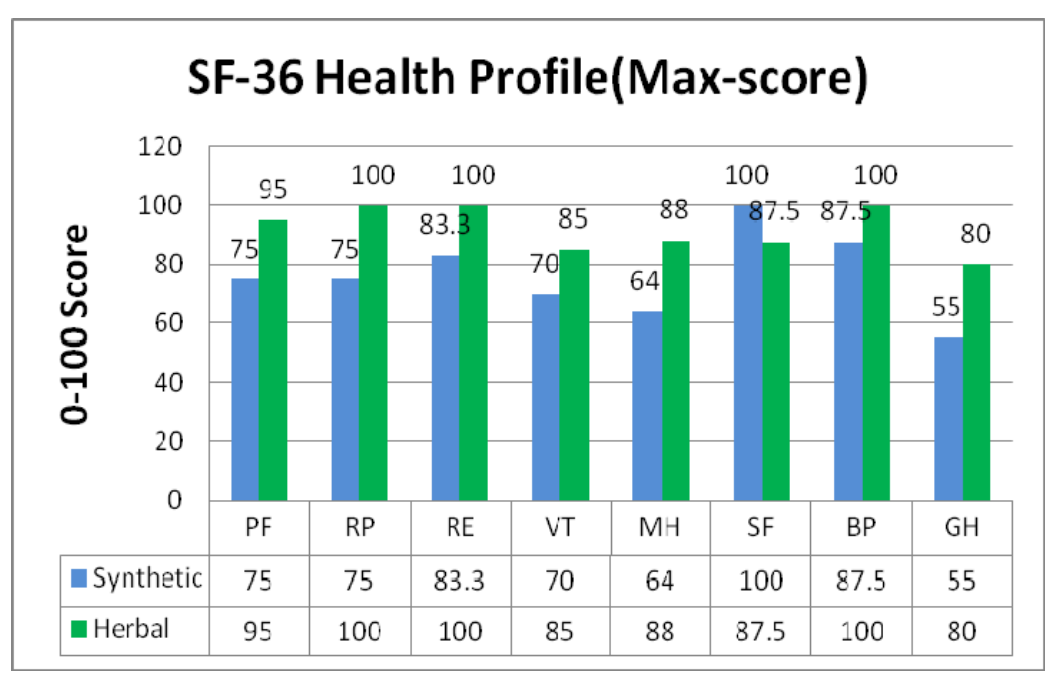

Fig. (2). Effect of treatment on generic health outcome measures (maximum scores) of diabetic patients. Descriptive statistics were given in terms of means and standard deviation, ceiling effect and flooring effect. The mean subscales scores for patients on synthetic treatment ranging approximately from 40-64 showed an improvement in the score range from 50 to 65 with herbal treatment. The maximum subscale scores for patients on herbal treatment ranged from 80-100 whereas the scores for synthetic treatment ranged from 55-100.

Table 3. Correlation Coefficient of domains between herbal and Synthetic treatment.

\begin{tabular}{|c|c|c|}
\hline No & Domains & R values \\
\hline \hline 1 & VT & -0.22267 \\
\hline 2 & BP & -0.15454 \\
\hline 3 & MH & -0.04187 \\
\hline 4 & GH & 0.029408 \\
\hline 5 & PF & 0.071476 \\
\hline 6 & RP & 0.086691 \\
\hline 7 & SF & 0.089853 \\
\hline 8 & RE & 0.090495 \\
\hline
\end{tabular}

\section{DISCUSSION}

In descriptive statistics, low score indicates poor quality and high score indicates better quality of life. From the mean and maximum scores obtained we can say that Qol was found with the herbal treatment than the synthetic drugs treatment.

The results showed the correlation between the GH of herbal medicine treated group of patients and GH of synthetic medicine treated group of patients. There was a less positive correlation representing a difference among the general health perception between treatments.

In QOLID analysis, an overall general health rating score for diabetics on herbal treatment was compared to the synthetic treatment score and moreover the treatment with herbal medicine showed increased treatment satisfaction, vitality and was found to decrease symptom irritability.

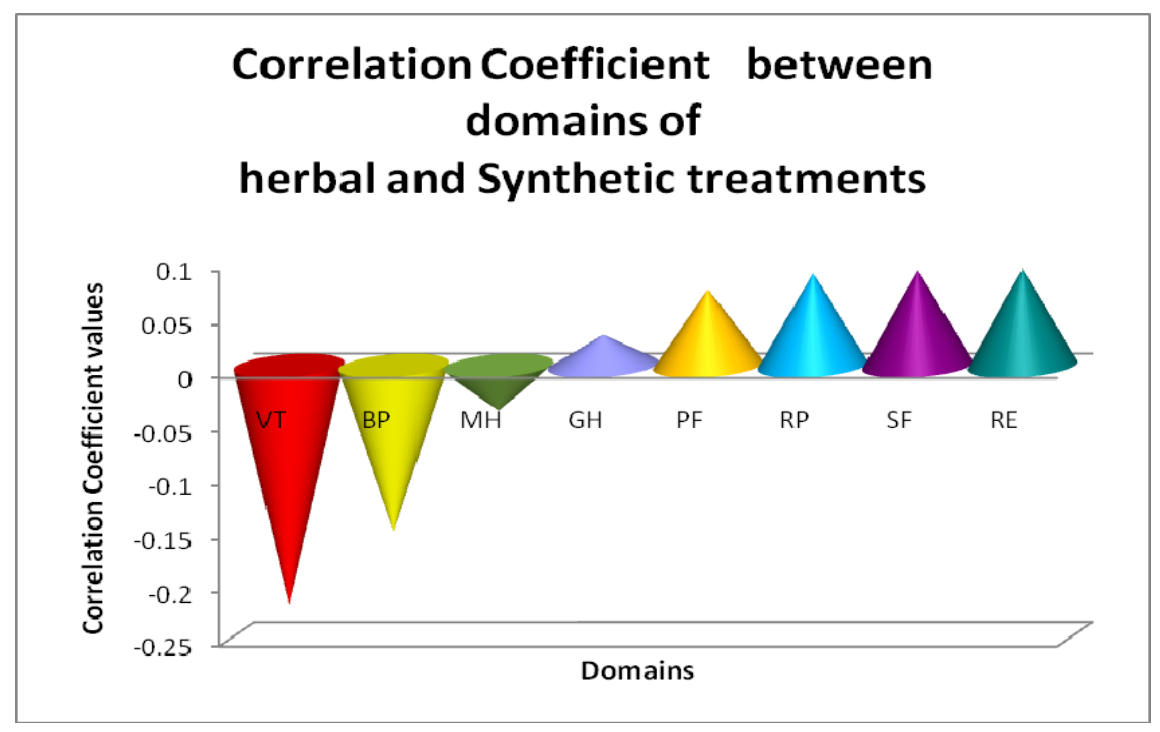

Fig. (3). An inter Correlation of domains between treatment groups. Correlation analysis which is one of the most widely used and reported statistical method in summarizing the medical and scientific data. The Pearson's correlation coefficients ranged from -0.22267 to 0.090495 . 
Table 4. Intra-correlations of each domain with the GH of synthetic medicine.

\begin{tabular}{|c|c|c|}
\hline S. No & Domains & Intra correlation \\
\hline \hline 1. & PH with GH & -0.2456 \\
\hline 2. & RP with GH & 0.24956 \\
\hline 3. & RE With GH & 0.644326 \\
\hline 4. & VT with GH & 0.48060 \\
\hline 5. & MH with GH & -0.01283466 \\
\hline 6. & SF with GH & -0.37716 \\
\hline 7. & BP with GH & -0.398206 \\
\hline
\end{tabular}

Table 5. Intracorrelations of each domain with the GH of Herbal medicine.

\begin{tabular}{|c|c|c|}
\hline S. No & Domains & Intra correlation \\
\hline \hline 1. & PH with GH & -0.07093 \\
\hline 2. & RP with GH & -0.018143 \\
\hline 3. & RE With GH & -0.01858 \\
\hline 4. & VT with GH & -.014263 \\
\hline 5. & MH with GH & 0.3278 \\
\hline 6. & SF with GH & -0.17325 \\
\hline 7. & BP with GH & -0.30331 \\
\hline
\end{tabular}

Table 6. Effect of herbal Treatment groups on the Actual and standardized score of Quality of life of Indian diabetic patients.

\begin{tabular}{|c|c|c|c|c|c|c|c|c|c|c|c|c|c|}
\hline Domains & $\begin{array}{l}\text { Cronbach's } \\
\text { alpha }\end{array}$ & $\begin{array}{c}\text { Actual } \\
\text { score } \\
\text { (Mean) }\end{array}$ & SD & $\begin{array}{l}\text { Max } \\
\text { score }\end{array}$ & $\begin{array}{c}\text { Standardized } \\
\text { score }\end{array}$ & 1 & 2 & 3 & 4 & 5 & 6 & 7 & 8 \\
\hline PH & 0.8657 & 25 & 4.1 & 30 & 83 & $0.521 * *$ & 1 & $0.740 * *$ & -0.017 & -0.152 & 0.144 & 0.162 & 0.150 \\
\hline PE & 0.8983 & 26 & 3.4 & 30 & 87 & $0.608 * *$ & $0.740 * *$ & 1 & 0.062 & 0.019 & $0.370^{*}$ & 0.223 & 0.264 \\
\hline SB & 0.5588 & 10 & 2.2 & 13 & 77 & 0.250 & -0.152 & -0.019 & $0.321^{*}$ & 1 & -0.017 & 0.208 & 0.169 \\
\hline FW & 0.3508 & 12 & 3.7 & 15 & 80 & 0.166 & 0.144 & $0.370^{*}$ & $-0.498 * *$ & -0.017 & 1 & 0.145 & $0.738 * *$ \\
\hline MH & 0.7423 & 17 & 1.9 & 23 & 74 & -0.026 & 0.162 & 0.223 & -0.084 & 0.208 & 0.145 & 1 & $0.327^{*}$ \\
\hline
\end{tabular}

**Significant at the 0.01 level * Significant at the 0.05 level

Table 7. Effect of synthetic Treatment groups on the Actual and standardized score of Quality of life of Indian diabetic patients.

\begin{tabular}{|c|c|c|c|c|c|c|c|c|c|c|c|c|c|}
\hline Domains & $\begin{array}{c}\text { Cronbach's } \\
\text { alpha }\end{array}$ & $\begin{array}{l}\text { Actual } \\
\text { score } \\
\text { (Mean) }\end{array}$ & SD & $\begin{array}{l}\text { Max } \\
\text { score }\end{array}$ & $\begin{array}{l}\text { Standardized } \\
\text { score }(\text { Mean } / \mathrm{m} \\
\text { ax. score*100) }\end{array}$ & 1 & 2 & 3 & 4 & 5 & 6 & 7 & 8 \\
\hline GH & 0.1159 & 8.2 & 1.4 & 12 & 68 & 1 & .130 & -0.069 & 0.190 & $0.404 * *$ & 0.257 & 0.275 & 0.034 \\
\hline PH & 0.7092 & 18 & 4.1 & 27 & 67 & 0.130 & 1 & 0.242 & -0.040 & $0.331 *$ & 0.207 & $0.451 * *$ & -0.299 \\
\hline PE & 0.6220 & 18 & 3.2 & 23 & 78 & -0.069 & .242 & 1 & -0.206 & -0.207 & 0.115 & -0.118 & 0.146 \\
\hline TS & 0.4970 & 12 & 2.2 & 17 & 71 & 0.190 & -.040 & -0.206 & 1 & 0.484 & 0.272 & 0.216 & 0.017 \\
\hline SB & 0.8300 & 9.3 & 3 & 15 & 62 & $0.404 * *$ & 0.331 & -0.207 & $0.484 * *$ & 1 & 0.321 & $0.693 * *$ & -0.213 \\
\hline FW & 0.4564 & 11 & 3.7 & 15 & 73 & 0.257 & 0.207 & 0.115 & 0.272 & 0.321 & 1 & 0.238 & $0.356^{*}$ \\
\hline MH & 0.7839 & 15 & 3.7 & 22 & 68 & 0.275 & $0.451 * *$ & -.118 & 0.216 & $0.693 * *$ & 0.238 & 1 & -0.299 \\
\hline DS & 0.0992 & 8.5 & 3.8 & 12 & 71 & 0.034 & -0.299 & .146 & 0.017 & -0.213 & 0.356 & -0.299 & 1 \\
\hline Overall & 0.8248 & & & & 69.75 & & & & & & & & \\
\hline
\end{tabular}

**Significant at the 0.01 level * Significant at the 0.05 level 


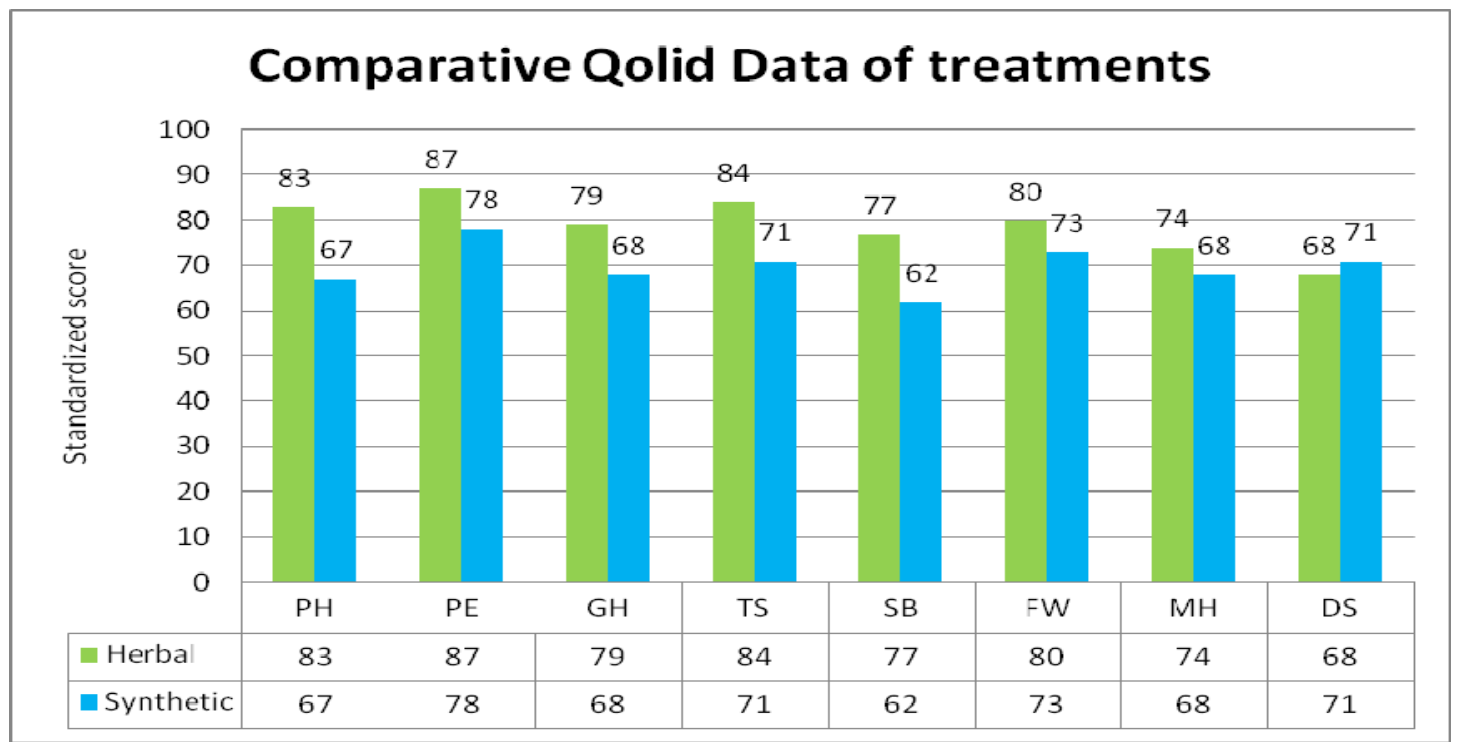

Fig. (4). Effect of Treatment groups on the Quality of life of Indian diabetic patients.

Future research on herbal medicine must pave its way concentrating on these specific domains of patient reported outcomes to improve the clinical effectiveness of the drug.

\section{CONCLUSION}

This study aimed at comparing the quality of life assessment of patients taking herbal medicine and allopathic medicine using generic and disease specific tools (SF-36 and QOLID). In SF-36 health profile, mean and maximum score values suggest a greater focus on the two facets of the variables named RE and SF of patient s comfort which help in complete maintenance of quality of life by herbal treatment. When compared to synthetic, herbals showed a better quality of life in variables of treatment satisfaction and general health from QOLID data. Current results suggest that treatment with herbal medicine is associated with increased satisfaction in almost all specific domains except the diet satisfaction, so future research on herbal medicine must pave its way concentrating on these specific domains of patient reported outcomes to improve the clinical effectiveness of the drug. Thus individualized instruments such as SF_36, QOlid may potentially be useful in assessing Herbal drugs for diabetes treatment.

\section{Future Implications and Limitations}

SF-6D version of SF-36 for economic evaluation has wide future implication in India. Translated brief versions like SF-12, SF-12V $\mathrm{V}^{\mathrm{TM}}$ and SF-8 $8^{\mathrm{TM}}$ can also be bridged and have broadened options for administration of DYNHADynamic health assessments. Study can be extended in assessing herbal medicines for disability adjusted life year DALYs (as disability is caused by diabetes).

Failure to recognize individual differences of the relative importance attached to various life domains leads to underestimation of QOL and has serious implications. Changes in the domains of life influence the QOL of the patients. Thus, identifying these factors influencing the patients QOL help to know about the treatment goal.
The study has some limitations with the foremost limitation being the duration of the study which was conducted in the period of 12 weeks; the second limitation is the sample size. The larger sample size would have improved the standardizability of results. The third one is the lack of randomization of patients relying on convenient sample. This drawback further limits the extrapolation of results to others; therefore further research is needed to overcome the limitations and to extend its applicability of results to other categories of patients. Outcomes have given information about the effect of alternative drug therapies on disease progression, survival, and the quality of life.
ABBREVIATIONS
$\mathrm{BP}$
$=$ Bodily Pain
DS $\quad=$ Diet Satisfaction
DSQOL $=$ Diabetes-Specific Quality of Life
$\mathrm{FW}=$ Financial Worries
GH $\quad=$ General Health
HRQOL = Health-Related Quality of Life
$\mathrm{MH}=$ Mental Health
$\mathrm{PE} \quad=$ Physical Endurance
$\mathrm{PF} \quad=$ Physical Functioning
QOL $=$ Quality of Life
QOLID $=$ Quality of life of Indian Diabetic Patients
$\mathrm{SB}=$ Symptom Botherness
SF-36-V2- = Short form health survey
TS $=$ Treatment Satisfaction
VT $\quad=$ Vitality

\section{CONFLICT OF INTEREST}

The authors confirm that this article content has no conflict of interest. 


\section{ACKNOWLEDGEMENTS}

Authors sincerely thank Dr. Satya Prasad, Head, Ayurvedic Hospital, Government Research Institute, Erragadda, Hyderabad, India for permitting to take the patient outcomes in the hospital, and also Thank the students Ganesh, Shalini, Sneha and surender for their help during the course of work.

\section{PATIENT'S CONSENT}

Declared none.

\section{REFERENCES}

[1] Hoareau, L.; Dasilva, E.J. Medicinal plants: a re-emerging health aid. Electron. J. Biotechnol., 1999, 2(2), 56-70.

[2] Etuk, E.U. Animal models for studying diabetes mellitus. Agric. Biol. J. N. Am., 2010, 1(2), 130-134.

[3] Ismail, R.S.A.; Abd El-Gawad, S.H. Potential effect of Egyptian anna apple pomace supplementation on Kidney function, Liver function and Lipid Profile of Diabetic rats. World J. Dairy Food Sci., 2010, 5(1), 58-66.

[4] Guyton and Hall, Text book of Medical Physiology, $10^{\text {th }}$ ed, 1996.

[5] Kerr, G.D.; Gamble, R.N.; Doughty, D.; Simmonst, Baker, J. Mortality in individuals with type 2 diabetes and heart in unique New Zealand population. Diabet. Med., 2006, 23(12), 1313-1318.

[6] Firuzi, O.; Lacanna, A.; Petrucci, R.; Marrusu, G.; Saso, L. Evaluation of the antioxidant activity of flavonoids by "Ferric reducing antioxidant power" assay and cyclic voltammetry. Biochem. Biophys. Acta., 2005, 1721(1-3), 174-184.

[7] Glise, H.; Wiklund, I. Health related quality of life and gastrointestinal disease. J. Gastroenterol. Hepatol., 2002, 17, S72-S84.
[8] Pu, C.; Tang, G.J.; Fang, Y.T.; Chou, Y.J. Which Domain of SelfRelated Health Best Predicts Medical Care Utilization Among Taiwanese Adults? J. Epidemiol., 2012, 22(5), 417-424.

[9] Holmanova, E.; Ziakova, K. Audit diabetes-dependent quality of life Questionnaire: Usefulness in diabetes self-management education in the Slovak population. J. Clin. Nurs., 2008, 18, 1276-1286.

[10] Anderson, R.M.; Fizgerald , J.T.; Wisom, K.; Davis, W.K.; Hiss, R.G. A comparison of global versus disease-specific quality-of-life measures in patients with NIDDM. Diabet. Care, 1997, 20, 299305 .

[11] Jacobson, A.M.; De Groot, M.; Samson, J.A. The evaluation of two measures of quality of life in patients with Type I and Type II Diabetes. Diabet. Care, 1994, 17, 267-74.

[12] William, H.; Polonsky. Understanding and assessing diabetesspecific quality of life. Diabet. Spect., 2000, 13, 36.

[13] Ware, J.H.; Sherbourne, C.D. The MOS 36-item short form health survey (SF-36) I: Conceptual framework and item selection. Med. Care, 1992, 30, 473-483.

[14] Ware, J.E.; Snow, K.K.; Kosinski, M.; Gandek, B. Application of SF-36 in SF-36 Health survey. Manual and Interpretation Guide, 1993, 11(1)

[15] Boye, K.S.; Matza, L.S.; Oglesby, A.; Malley, K.; Kim, S.; Hayes, R.P.; Brodows, R. Patient- reported outcomes in a trial of exenatide and insulin glargine for the treatment of Type 2 Diabetes. Health Qual. Life Outcomes, 2006, 4(80), 1-8.

[16] Nagpal, J.; Kumar, A.; Kakar, S.; Bhartia, A. The development of quality of life instrument for Indian diabetes patients (QOLID): A validation and reliability study in middle and higher income groups. J. Assoc. Physicians India., 2010, 58, 295-304.

[17] Pippalla, R.S.; Chinburapa, V.; Duval, R.; Akula, R.S. Interrelation ships of quality of life, compliance, clinical outcomes and life satisfaction: a cross-sectional study on hypertensive geriatrics. J. Clin. Pharm. Ther., 1997, 22, 357-369.

(C) Rani et al.; Licensee Bentham Open.

This is an open access article licensed under the terms of the Creative Commons Attribution Non-Commercial License (http://creativecommons.org/licenses/by-nc/3.0/) which permits unrestricted, non-commercial use, distribution and reproduction in any medium, provided the work is properly cited. 